\title{
ALTERAÇÕES DO USO DA TERRA NA PONTA DA PRAIA E NO PONTAL DA TRINCHEIRA, MUNICÍPIO DE ILHA COMPRIDA (SP), ENTRE OS CENÁRIOS DE 1972 E DE 2012
}

\author{
Tissiana de Almeida de Souza ${ }^{(a)}$ Regina Célia de Oliveira ${ }^{(b)}$ \\ (a) Pós-Doutoranda - Departamento de Planejamento Territorial e Geoprocessamento - DEPLAN/IGCE, UNESP - \\ Rio Claro, tissisouza@yahoo.com.br \\ (b) Professora - Departamento de Geografia - DGEO/IG, UNICAMP - Campinas, reginacoliveira@ige.unicamp.br
}

\section{Eixo: Uso e Ocupação das Terras e Legislação Ambiental}

\begin{abstract}
Resumo
Este trabalho tem como objetivo analisar as alterações de uso da terra ocorridas no Pontal da Trincheira e na Ponta da Praia, situados, respectivamente nas extremidades Sudoeste e Nordeste do município de Ilha Comprida, através da interpretação das cartas de uso da terra elaboradas na escala original 1:10.000 para os cenários de 1972 e de 2012. A seleção destes dois setores é justificada pela sobreposição de Unidades de Conservação da Natureza, e pela ocorrência de duas situações distintas relacionadas aos zoneamentos determinados para estas áreas. Como resultado, observa-se que a Ponta da Praia apresenta uma intervenção antrópica e uma densidade demográfica superior àquela encontrada no Pontal da Trincheira. A sobreposição de três Unidades de Conservação na extremidade Nordeste da Ilha também gera dúvidas com relação ao uso da terra que é permitido na área.
\end{abstract}

Palavras chave: Uso da terra. Unidades de Conservação. Litoral.

\section{Introdução}

Historicamente, a zona litorânea do Estado de São Paulo foi uma das primeiras áreas do Brasil a serem ocupadas pelos portugueses. A Barra de Cananeia, localizada no setor sul do litoral paulista, era considerada ponto estratégico para a formação de um núcleo colonizador, onde havia boas condições para atracação de embarcações e desenvolvimento do comércio (AFONSO, 1999).

Em 1531, a expedição de Martim Afonso de Souza chega à Barra de Cananeia e se instala na Vila de Maratayama (ou Vila dos Tupis), na época situada na Ilha Comprida, e que é considerada pelo Instituto Brasileiro de Geografia e Estatística (IBGE, 2017) como a primeira vila oficial da Coroa Portuguesa no Brasil colônia.

Apesar da importância histórica ao povoamento do Brasil, nos séculos seguintes a ocupação na Ilha Comprida foi caracterizada pela presença de pequenas vilas, que se formaram com o objetivo de abrigar viajantes, correios e paradeiros. Estas vilas surgiam e desapareciam ao longo do tempo (CARVALHO, 1999). 
A ocupação urbana da Ilha Comprida teve início, efetivamente, na década de 1950, com crescimento nas décadas de 1970 e 1980 (FARINACCIO, 2008). Henrique e Mendes (2001) ressaltam que a superlotação e a poluição das praias da Baixada Santista propiciaram a "redescoberta" do litoral sul, o que incentivou a especulação imobiliária na região.

Souza e Oliveira (2016) afirmam que a partir da década de 1980, a abertura de loteamentos e de arruamentos foram as principais situações responsáveis por importantes modificações nas classes de uso da terra na Ilha Comprida, sobretudo em seus setores central e nordeste. Dentre estas mudanças, destacamse a retirada de restinga e o isolamento de fragmentos florestais deste tipo de vegetação; o desmatamento das áreas de mangues, em substituição pelas classes de solo exposto e de gramíneas; o desenvolvimento da área residencial e comercial, com mancha urbana principal localizada no trecho nordeste da ilha; e, a eliminação da vegetação que recobre as dunas frontais.

Além da fragmentação da Ilha Comprida em diversos balneários, a década de 1980 também ficou marcada pela criação e regulamentação de Unidades de Conservação da Natureza (UCs) de nível Federal e de nível Estadual, que englobaram o território da ilha visando a proteção de suas características naturais e culturais, inclusive, visando a orientação para a ocupação e os usos da terra.

Segundo Anderson et al. (1979), a carta de uso da terra é um recurso que colabora com planejadores e com legisladores de diferentes níveis de governo na organização de políticas públicas de desenvolvimento regional e de uso da terra. Estes documentos cartográficos auxiliam na identificação de pontos sujeitos à pressão antrópica e no entendimento dos atuais padrões de vida e condições ambientais.

Com base nas considerações apresentadas, o objetivo deste trabalho é analisar as alterações de uso da terra ocorridas no Pontal da Trincheira e na Ponta da Praia, situados, respectivamente nas extremidades sudoeste e nordeste da Ilha Comprida, através da interpretação das cartas de uso da terra elaboradas na escala original 1:10.000, para os cenários de 1972 e de 2012.

A seleção dos dois pontos terminais da ilha é justificada pela sobreposição de Unidades de Conservação, e pela ocorrência de duas situaçãos distintas relacionadas aos zoneamentos determinados para estas áreas. As extremidades da ilha são também setores de intensa dinâmica natural lagunar, fluvial e marinha, onde constantemente ocorrem processos de recuos e de avanços da linha de costa e da margem lagunar.

O município de Ilha Comprida apresenta uma área territorial de $192 \mathrm{~km}^{2}$ (IBGE, 2017) e está situado no litoral sul do Estado de São Paulo, a cerca de $210 \mathrm{~km}$ da capital. A ilha é isolada pelos canais lagunares do Mar de Cananeia (ou Mar de Fora) e do Mar Pequeno (ou Mar de Iguape) e estende-se por cerca de 63km, entre desembocadura lagunar de Icapara e a Barra de Cananeia. A Figura 1 mostra a localização 
geográfica da Ilha Comprida e os quadrados vermelhos enfatizam o Pontal da Trincheira e a Ponta da Praia.

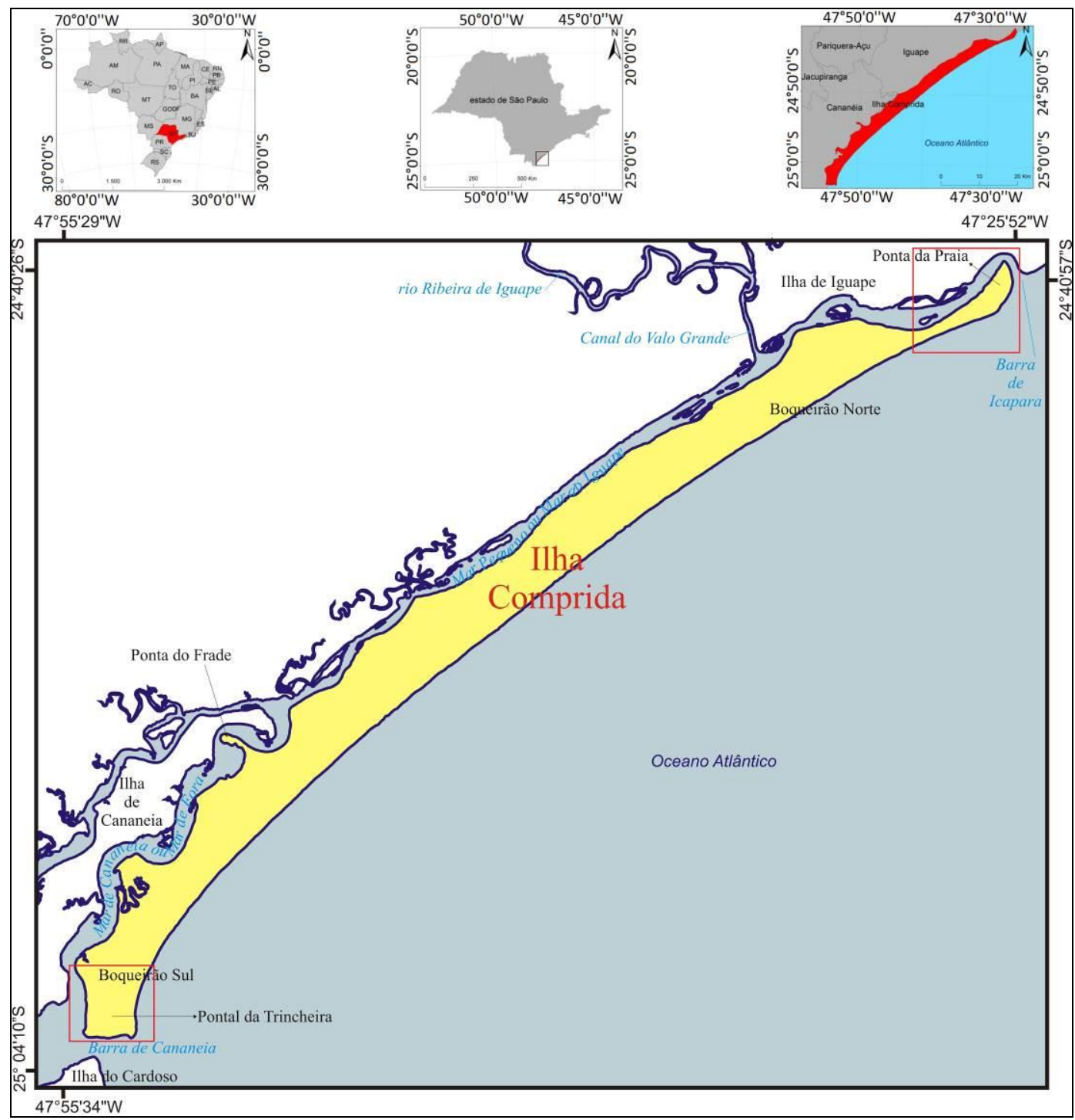

Figura 1 - Localização geográfica do município de Ilha Comprida, com destaque para as extremidades NE e SW, evidenciadas pelos quadrados na cor vermelha.

Fonte: organização das autoras (2016); adaptado de $\operatorname{IBGE}(1973,1974,1983,1986,2014)$.

A Ilha Comprida integra o Complexo Estuarino-Lagunar de Cananeia-Iguape, conhecido regionalmente como "Lagamar", que se caracteriza pela presença de mares interiores, ilhas, manguezais e restingas e é considerado Patrimônio Natural da Humanidade pela UNESCO.

\section{As Unidades de Conservação (UCs) da Natureza e a Emancipação Municipal da Ilha Comprida}




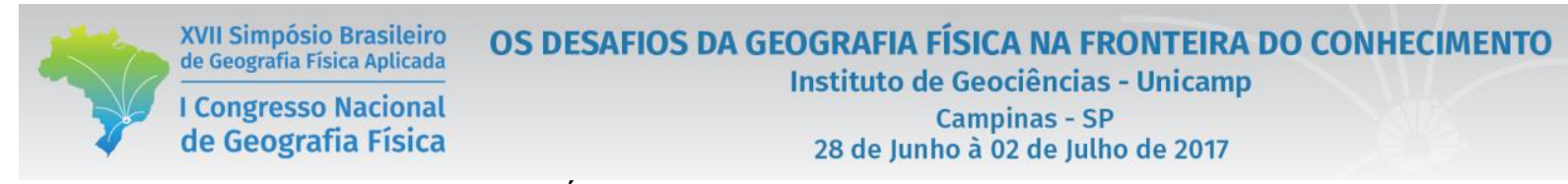

A Ilha Comprida integra três UCs: a Área de Proteção Ambiental Cananeia-Iguape-Peruíbe (APA CIP), a APA da Ilha Comprida e a Área de Relevante Interesse Ecológico do Guará (ARIE do Guará). A Figura 2 mostra a disposição das UCs sobre o território municipal, com a ocorrência de sobreposição entre estas:

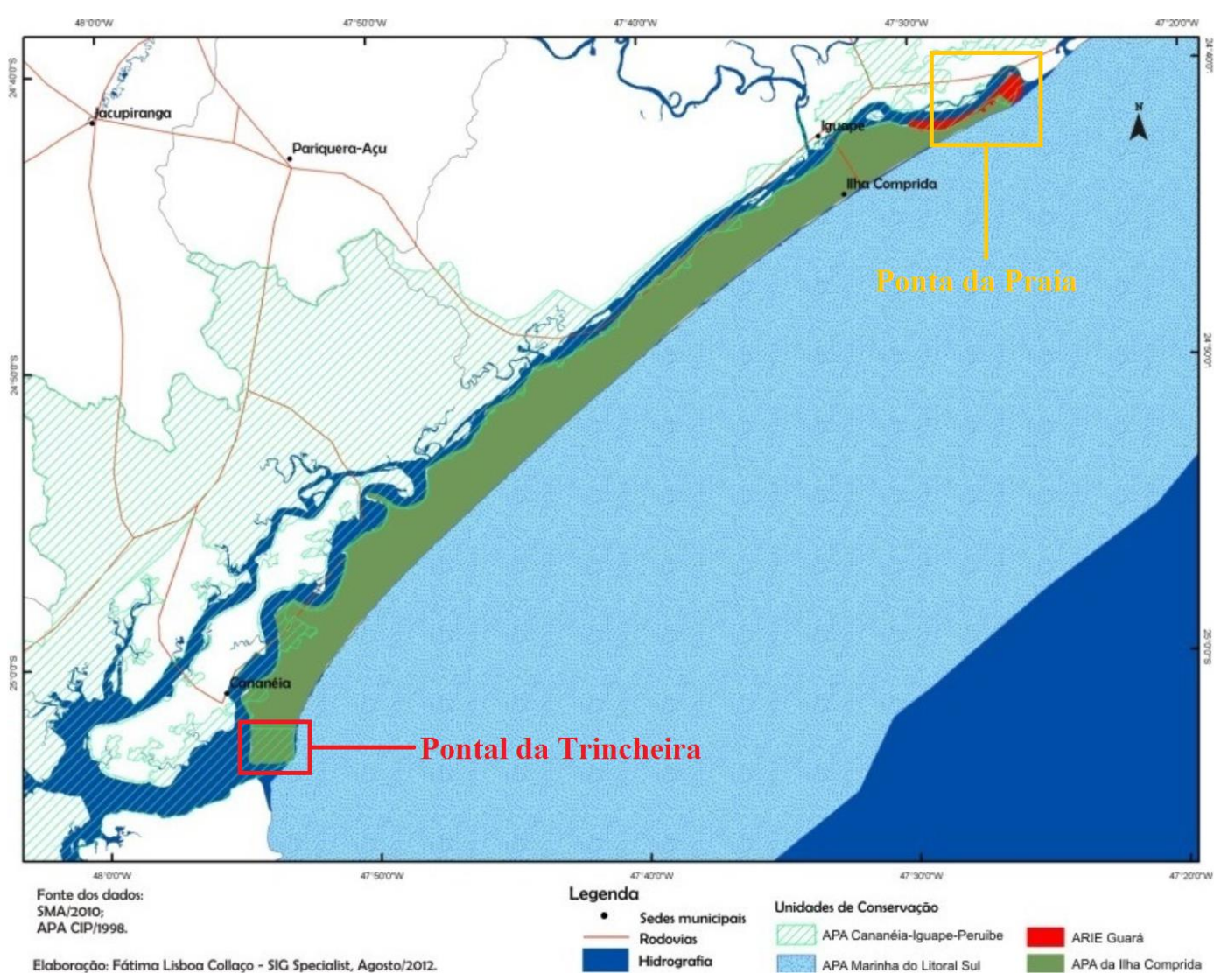

Figura 2 - Sobreposição de Unidades de Conservação na Ilha Comprida. Fonte: Adaptado de COLLAÇO (2012). A APA CIP foi criada através do Decreto Federal n ${ }^{\circ} 90.347$, de 23/10/1984. Conforme o Art. $2^{\circ}$ do Decreto, os objetivos para a instituição da Unidade de Conservação foram proteger espécies vegetais, sítios arqueológicos, regiões de nidificação de aves, espécies animais ameaçadas de extinção e manter a qualidade de seus recursos hídricos.

De acordo com São Paulo (2004), o grande incentivo para instituir a APA da Ilha Comprida foi o parcelamento do solo e a formação de loteamentos, muitos destes irregulares, e que colocavam em risco o equilíbrio ambiental da região. A criação da APA se deu através do Decreto Estadual n²6.881, de 11/03/1987. O Decreto Estadual n²8.295, de 21/03/1988 suspendeu o licenciamento e a aprovação de quaisquer formas de parcelamento do solo na APA até sua regulamentação. Por último, o Decreto 
Estadual no30.817, de 30/11/1989, regulamenta a UC, determina o zoneamento e estabelece condições para o parcelamento do solo e sua ocupação.

Segundo o Decreto n²6.881 (SÃO PAULO, 1987) outros argumentos utilizados para o estabelecimento da APA da Ilha Comprida foram: a existência de núcleos tradicionais de pescadores; a função como ilhabarreira; a localização no Complexo Estuarino-Lagunar; as características do sistema de drenagem; a presença de organismos aquáticos passíveis de cultivo e seu potencial para aquicultura; a importância como refúgio de espécies marinhas e aves migratórias; e, a inter-relação entre vegetação-fauna-solo-água.

O Art. $8^{\circ}$ do Decreto Estadual n53.527 de 08/10/2008 cria a Área de Relevante Interesse Ecológico do Guará (ARIE do Guará), com o objetivo de resguardar aves migratórias que se alimentam no trecho nordeste da Ilha Comprida.

A emancipação municipal de Ilha Comprida ocorreu em 05/03/1992, e em 07/12 do mesmo ano, o município foi elevado à condição de Estância Balneária.

A Lei Orgânica do Município (de 30/06/1993) estabelece no Art.5 $5^{\circ}$ que é competência municipal a elaboração de Plano Diretor. Segundo a Lei Federal n¹0.257 de 10/07/2001 (Estatuto da Cidade), Art.41, o Plano Diretor é obrigatório para cidades com especial interesse turístico, ainda que possuam população inferior a 20.000 habitantes, como é o caso da Ilha Comprida. O Plano Diretor de Desenvolvimento Integrado encontra-se em fase de discussão desde o final do ano de 2014.

O Art.94 da Lei Orgânica determina que a definição da Zona de Expansão Urbana e da Zona Urbana ocorrerão através de Lei, e quando for necessário, observado o caso estabelecido pelo Plano Diretor. Não foi considerada a pré-existência do zoneamento estabelecido pela APA da Ilha Comprida, que define Zonas Urbanizadas e Zonas de Ocupação Controlada.

\section{Materiais e Técnicas de Elaboração das Cartas de Uso da Terra}

A Carta de Uso da Terra do cenário 1972 foi organizada a partir de pares estereoscópicos de fotografias áereas digitalizadas, na escala original 1:25.000. Os pares estereoscópicos foram trabalhados no aplicativo StereoPhoto Maker ${ }^{\circledR}$, conforme com os procedimentos técnicos de Souza e Oliveira (2012), que possibilitaram a geração de imagens tridimensionais que posteriormente foram interpretadas diretamente na tela do computador com a utilização de óculos 3D comum.

A Carta de Uso da Terra de 2012 foi elaborada através de mosaico de imagens orbitais do satélite Worldview-2, na escala 1:15.000, com composição colorida RGB fusionado e resolução espacial de $0,5 \mathrm{~m}$. 
As imagens tridimensionais e as imagens orbitais foram georreferenciadas no software ArcGIS ${ }^{\circledR}$ utilizando-se a Base Cartográfica da área de estudo, em escala 1:10.000, elaborada a partir de 25 folhas topográficas adquiridas junto ao Instituto Geográfico e Cartográfico do Estado de São Paulo (IGC-SP, 1989). Em seguida, foi realizada a análise visual das imagens e a demarcação manual das classes.

As classes de uso da terra foram definidas a partir do Sistema de Classificação de Uso da Terra e do Revestimento do Solo para Utilização com Dados de Sensores Remotos (ANDERSON et al., 1979), por apresentar maior adaptabilidade às tipologias de uso da terra ocorrentes na Ilha Comprida.

\section{Resultados e discussão}

A interpretação das cartas de uso da terra para os cenários de 1972 e de 2012 concomitante à análise da legislação ambiental das UCs revelam situações distintas para as extremidades da ilha.

A Figura 3 mostra as Cartas de Uso da Terra elaboradas para o Pontal da Trincheira. Observa-se como característica principal, para os dois cenários, a predominância de mancha contínua de vegetação de restinga e a presença de vegetação de dunas próximo à Praia do Pontal (Figura 4) e ao Pontal na margem oceânica.

No cenário de 1972, as manchas de solo exposto e de vegetação rasteira se destacam na margem lagunar, sendo relacionadas com ocupação humana. Verifica-se a ocorrência da classe de depósitos arenosos às margens do Mar de Cananeia, que se associa com a disponibilidade de material no canal lagunar. Caminhos e trilhas para deslocamento dos moradores se estendem da Praia do Pontal à margem interna.

Para o cenário de 2012, constata-se uma pequena mancha urbana relacionada com o Boqueirão Sul (Zona de Ocupação Controlada 2 - APA da Ilha Comprida), onde a vegetação de restinga e a vegetação de dunas foi substituída por gramíneas e solo exposto nas proximidades com a praia arenosa. Tal fato pode resultar em reativação das feições dunares que estavam anteriormente estabilizadas e as areias podem migrar de local, passando a utilizar as edificações como pontos de ancoragem.

No cenário de 2012, as estradas não-pavimentadas correspondem a arruamentos dos Balneários, porém sem a presença de construções.

Edificações pontuais e manchas de gramíneas mostram os locais de ocupação humana na margem lagunar. 


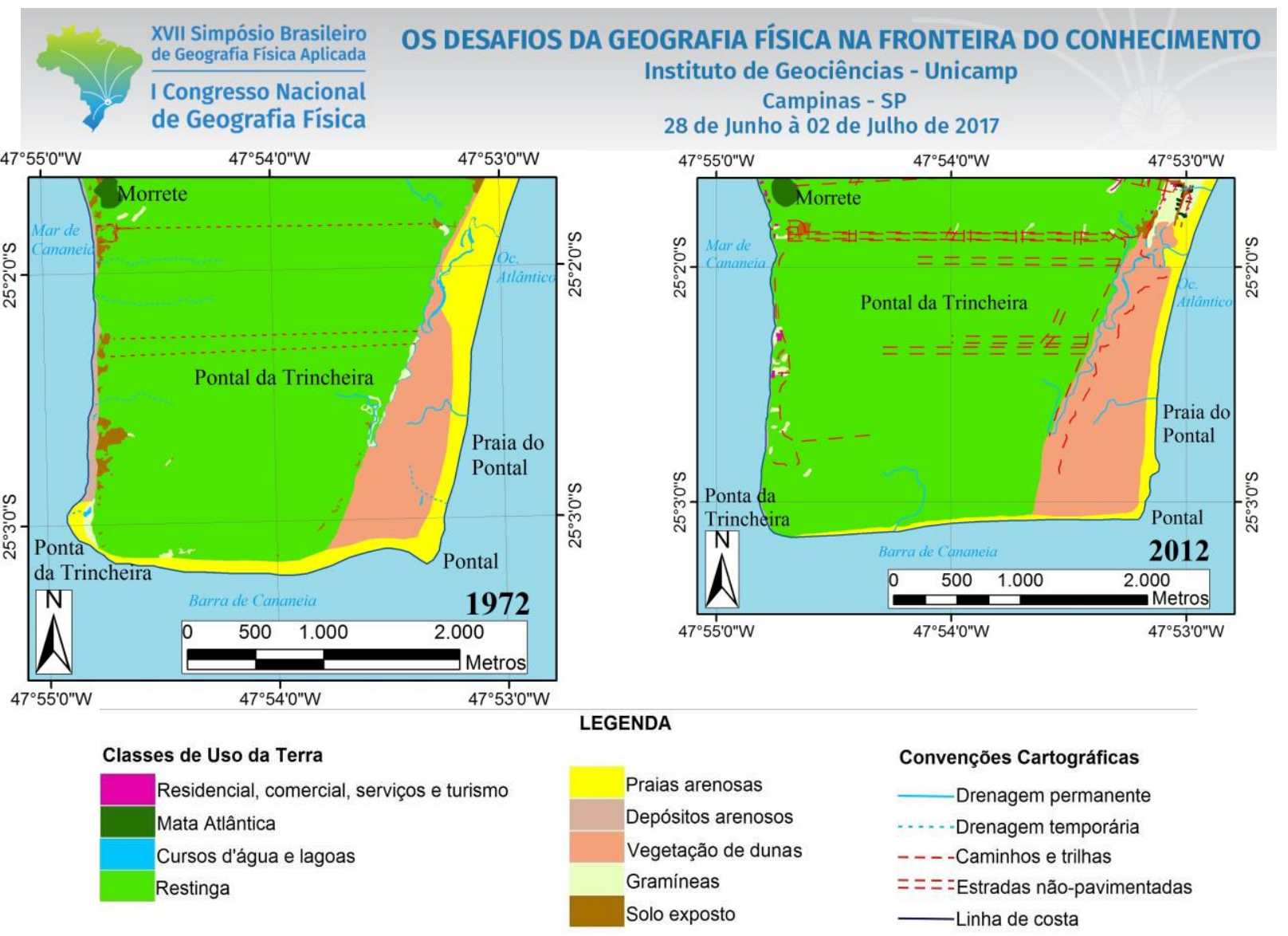

Figura 3 - Alterações de uso da terra entre os cenários de 1972 e de 2012 para o Pontal da Trincheira, extremidade Sudoeste da Ilha Comprida. Organização das autoras.

Nos dois cenários constata-se significativa alteração das praias arenosas, mostrando uma tendência erosiva da linha de costa. Tessler et al. (1990) afirmam que a erosão na Ponta da Trincheira é resultante da retenção das águas nos canais lagunares durante eventos climáticos, que na maré vazante subsequente podem provocar o rompimento desta extremidade. Souza (2014) constatou que entre 1976 e 2011, a Ponta da Trincheira recuou mais de 100m. Para o Pontal, Tessler et al. (1990) ressaltam que os processos erosivos estão ligados à predominância das correntes de maré vazante que atuam na Barra de Cananeia. Segundo Souza (2014), entre 1976 e 2011, o Pontal apresentou retrogradação costeira acima de 200m.

No que diz respeito à legislação ambiental, o Pontal da Trincheira é considerado como Zona de Vida Silvestre pelo Decreto Federal nº $90.347 / 84$ e pelo Decreto Estadual nº30.817/89, sendo área destinada à manutenção das características naturais da paisagem. Apesar da sobreposição de duas UCs de diferentes níveis de governo, ambas objetivam o mesmo uso para este setor da Ilha Comprida.

As Cartas de Uso da Terra mostram uma baixa ocupação no Pontal da Trincheira, com edificações espacialmente dispersas, comprovadas pelos dados do Censo Demográfico (IBGE, 2010), que apontam densidade demográfica, de 1,45 a $44,65 \mathrm{hab} . / \mathrm{km}^{2}$. O fato de ser uma área pouco ocupada contribui para a preservação da vegetação natural (Figura 5). 


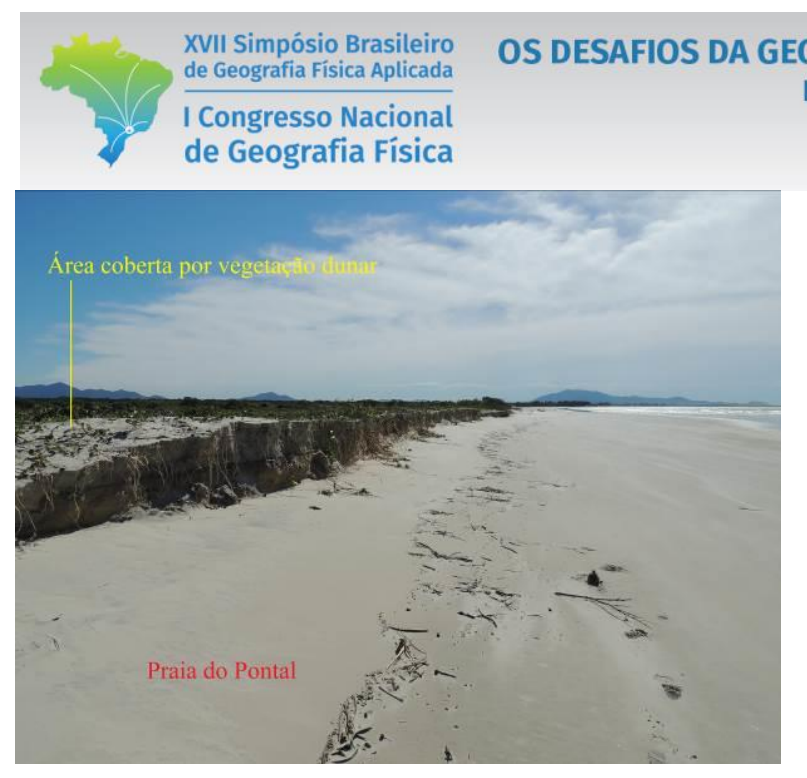

Figura 4 - Praia do Pontal, na extremidade SW da Ilha Comprida, com trecho de vegetação dunar ao lado esquerdo da foto. Autora: SOUZA, T. A. (2014)
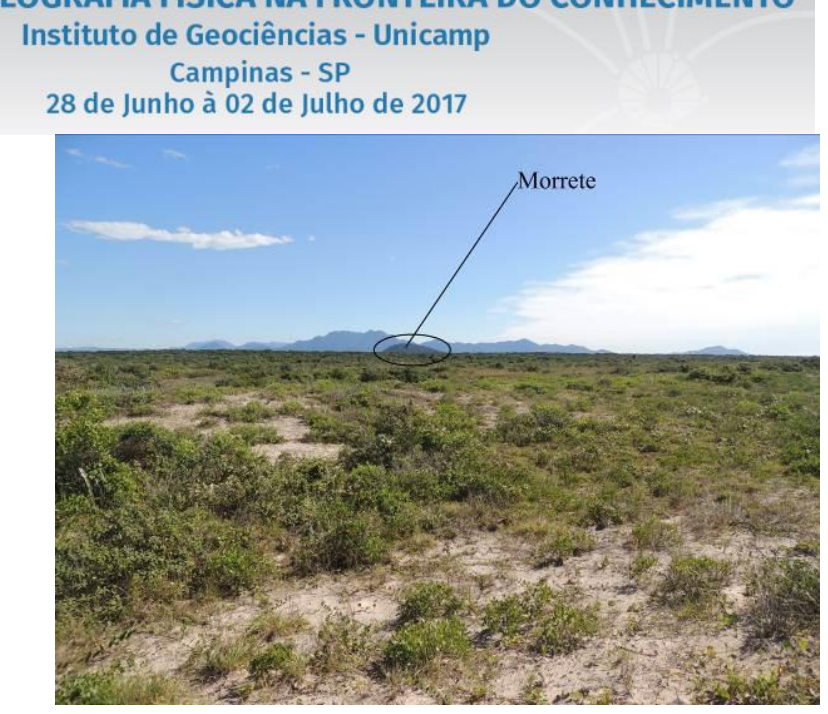

Figura 5 - Pontal da Trincheira, observado em direção ao Morrete, situado na margen lagurar da Ilha. Área de vegetação natural e baixa ocupação humana. Autora: SOUZA, T. A. (2014).

No que concerne à Ponta da Praia (Figura 6), a análise dos produtos cartográficos de 1972 e 2012 mostra uma evolução temporal distinta daquela apresentada pelo Pontal da Trincheira.

No cenário mais antigo, observa-se que as intervenções humanas são ausentes entre o Campo de Dunas do Araçá e a Barra de Icapara. No entanto, em 1972 a área já apresenta um loteamento - Praia do Araçá localizado nas proximidades da transição entre dunas fixadas por vegetação e as dunas não estabilizadas.

No cenário de 2012, verifica-se a presença de uma estrada pavimentada que atravessa o Campo de Dunas; o desaparecimento da vegetação de dunas no Balneário Praia do Araçá, em substituição por gramíneas; a ocorrência de loteamentos e edificações entre o campo dunar e a Barra de Icapara.

Nos Balneários Saveiros, Mares do Pontal e Ana Cristina, residências e estabelecimentos comerciais são encontrados no interior do Campo de Dunas do Araçá, sobre areias em constante retrabalhamento eólico (Figura 7).

De acordo com IBGE (2010), a densidade demográfica neste setor é de 76,27 a 231,57hab./km². Apesar de não apresentar os maiores valores relacionados com a ocupação humana da ilha, este trecho certamente é o mais problemático com relação à erosão costeira.

As Cartas de Uso da Terra mostram uma expressiva alteração da linha de costa, com arredondamento e progradação da extremidade na Barra de Icapara. Entre 1882 e 1965, o deslocamento da linha de costa em direção a nordeste teria sido da ordem de +2.800m (+35m/ano) (GEOBRÁS, 1966). Entre 1976 e 2011, segundo Souza e Oliveira (2014), o avanço foi de $+1.233 \mathrm{~m}$, também com média de $+35 \mathrm{~m} / \mathrm{ano}$. 

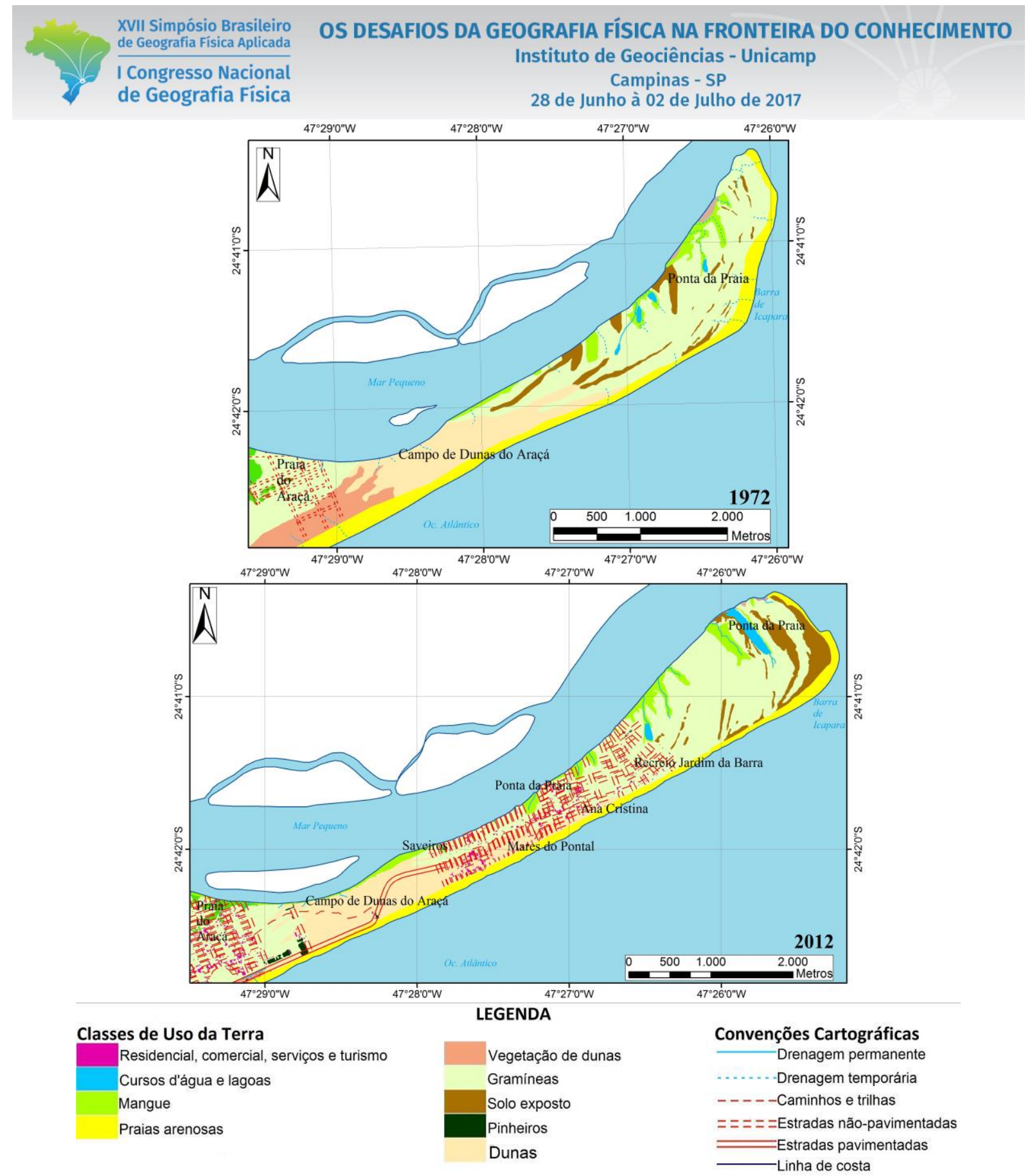

Figura 6 - Modificações do uso da terra na Ponta da Praia, extremidade Nordeste da Ilha Comprida, cenários de 1972 e 2012. Organização das autoras.

Na Praia da Ilha Comprida ocorrem processos erosivos que alcançaram valores, entre 1976 e 2011, de 290m, e média de -8,2m/ano (SOUZA; OLIVEIRA, 2014). As principais consequências da erosão são a destruição de edificações (Figura 8) e a derrubada de postes de energia elétrica e árvores, como pôde ser observado durante trabalhos de campo efetuados na área entre 2011 e 2014. 

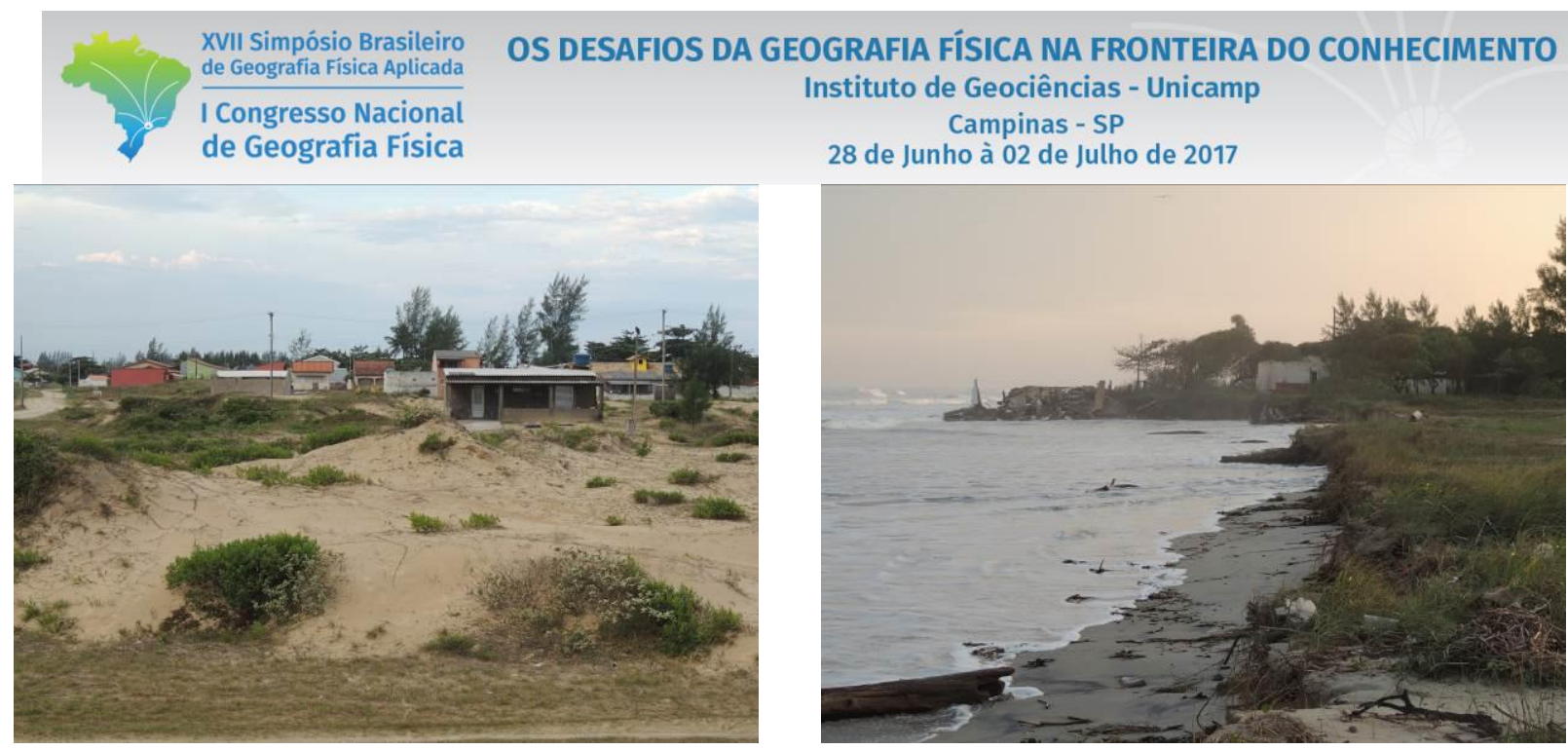

Figura 7 - Edificações localizadas na área do Campo de Dunas do Araçá. Autora: SOUZA, T. A. (2014).

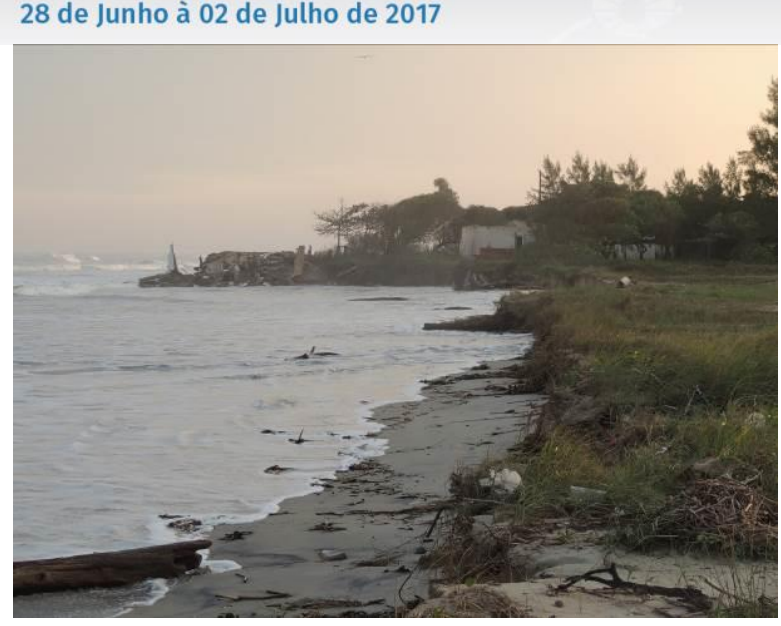

Figura 8 - Erosão costeira na Praia da Ilha Comprida. Autora: SOUZA, T. A. (2014).

A extremidade NE é caracterizada pela sobreposição de três UCs, o que dificulta o entendimento das permissões e restrições ao uso da terra. Segundo o Decreto Federal $n^{\circ} 90.347 / 84$, esta área é considerada Zona de Vida Silvestre, que tem como objetivo a manutenção da biodiversidade. De acordo com o o zoneamento instituído pelo Decreto Estadual n³0.817/89, este trecho é Zona de Proteção Especial (ZPE), onde não é permitido o parcelamento do solo. Entretanto, o Art.18 deste mesmo decreto abre exceção para a execução de obras de qualquer natureza, desde que seja concedida autorização prévia.

O Decreto Estadual nº53.527/08 determina a criação da Área de Relevante Interesse Ecológico do Guará, ainda sem Plano de Manejo e zoneamento.

\section{Considerações finais}

Os produtos cartográficos apresentados mostram dinâmicas diferentes de uso da terra para as extremidades da Ilha Comprida. No Pontal da Trincheira, a baixa ocupação em conjunto com a sobreposição de um zoneamento com os mesmos objetivos possibilita a manutenção dos tipos vegetacionais, geomorfológicos e geológicos da área, com poucas intervenções humanas.

A Ponta da Praia é caracterizada pelo crescimento de intervenções humanas entre 1972 e 2012, com a abertura de loteamentos e arruamentos que ocorrem, inclusive, sobre o Campo de Dunas do Araçá. A sobreposição de três UCs, com determinação de difentes zonas para a APA CIP e para a APA Ilha Comprida e a ausência de zoneamento para a ARIE do Guará, levanta dúvidas sobre os usos da terra que são permitidos ou restritos nesta área. 


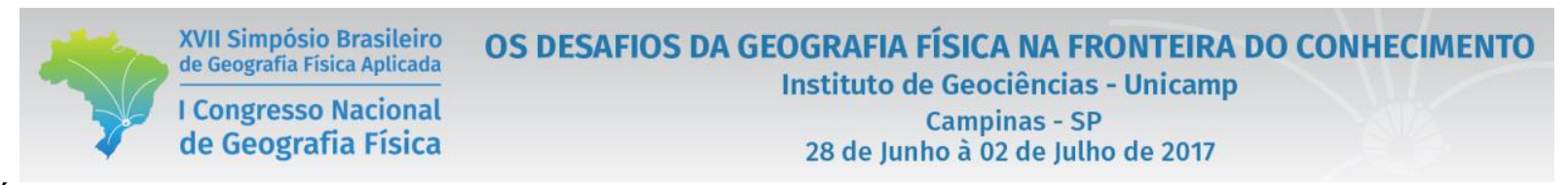

É necessário que os Planos de Manejos que serão elaborados para as UCs adequem as áreas comuns com as mesmas finalidades para proteção, conservação, preservação e uso das terras.

A elaboração Plano Diretor de Desenvolvimento Integrado da Ilha Comprida não pode desconsiderar a presença das Unidades de Conservação. A Prefeitura Municipal e os Conselhos Gestores necessitam de trabalho integrado para a realização do zoneamento da ilha.

\section{Agradecimentos}

As autoras agradecem à FAPESP - Fundação de Amparo à Pesquisa do Estado de São Paulo - pelo financiamento da pesquisa (Processo nº2011/09859-9).

\section{Bibliografia}

AFONSO, C. M. Uso e ocupação do solo na zona costeira do estado de São Paulo: uma análise ambiental. São Paulo: Annablume/FAPESP, 1999.

ANDERSON, J. R. et al. Sistema de classificação do uso da terra e do revestimento do solo para utilização com dados de sensoriamento remoto. Rio de Janeiro: IBGE, 1979.

BRASIL. Decreto $\mathbf{n}^{\circ} \mathbf{9 0 . 3 4 7}$ (1984). Lex: dispõe sobre a implantação da Área de Proteção Ambiental nos municípios de Cananeia, Iguape, e Peruíbe, no Estado de São Paulo, e dá outras providências. Brasil, 1984.

BRASIL. Lei $\mathbf{n}^{0} 10.257$ (2001). Lex: regulamenta os arts. 182 e 183 da Constituição Federal, estabelece diretrizes gerais da política urbana e dá outras providências. Brasília: Senado Federal, 2001.

CARVALHO, M. C. P. Histórias da ilha: temporalidade e apropriação do espaço na Ilha Comprida. 1999. 199 f. Dissertação (Mestrado em Antropologia) - Instituto de Filosofia e Ciências Humanas, Universidade Estadual de Campinas, Campinas.

FARINACCIO, A. Impactos da dinâmica costeira decorrentes das intervenções em praias arenosas e canais estuarinos das áreas densamente ocupadas no litoral de São Paulo, uma aplicação do conhecimento a áreas não ocupadas. 2008. 229 f. Tese (Doutorado em Ciências) - Instituto de Oceanografia, Universidade de São Paulo, São Paulo.

GEOBRÁS S/A. Complexo Valo Grande, Mar Pequeno e Rio Ribeira de Iguape. Relatório GEOBRÁS S/A. São Paulo: Engenharia e Fundações para o Serviço do Vale do Ribeira do Departamento de Águas e Energia Elétrica. 2 volumes. 1966.

HENRIQUE, W; MENDES, I. A. Zoneamento ambiental em áreas costeiras: uma abordagem geomorfológica. In: GERARDI, L. H.; MENDES, I. A. (Org.). Teoria, técnicas, espaços e atividades: temas de geografia contemporânea. Rio Claro: Programa de Pós-Graduação em Geografia/Associação de Geografia Teorética AGETEO, 2001. cap. 9.

INSTITUTO BRASILEIRO DE GEOGRAFIA E ESTATÍSTICA (IBGE). Subaúma. Rio de Janeiro: IBGE, 1973. 1 mapa. Escala 1:50.000.

INSTITUTO BRASILEIRO DE GEOGRAFIA E ESTATÍSTICA (IBGE). Ilha de Cananeia. Rio de Janeiro: IBGE, 1974. 1 mapa. Escala 1:50.000.

INSTITUTO BRASILEIRO DE GEOGRAFIA E ESTATÍSTICA (IBGE). Cananéia. Rio de Janeiro: IBGE, 1983. 1 mapa. Escala 1:50.000. 


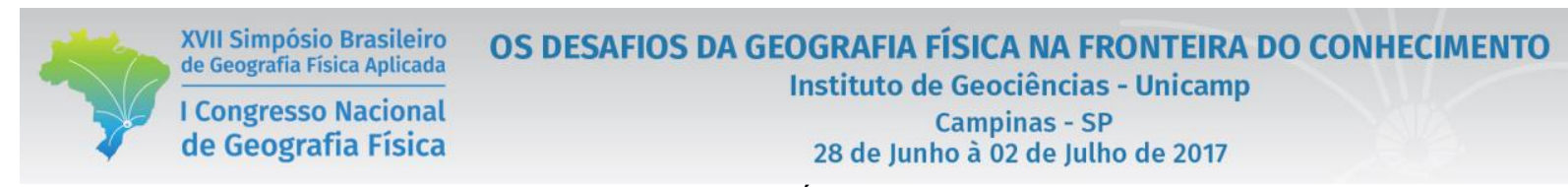

INSTITUTO BRASILEIRO DE GEOGRAFIA E ESTATÍSTICA (IBGE). Iguape. Rio de Janeiro: IBGE, 1986. 1 mapa. Escala 1:50.000.

INSTITUTO BRASILEIRO DE GEOGRAFIA E ESTATÍSTICA (IBGE). Sinopse do Censo Demográfico 2010. Disponível em: < http://www.censo2010.ibge.gov.br/sinopse/index.php> Acesso em: 06 Set. 2014.

INSTITUTO BRASILEIRO DE GEOGRAFIA E ESTATÍSTICA (IGBE). Base Cartográfica do Brasil ao Milionésimo. Rio de Janeiro: IBGE, 2014. Escala 1:1.000.000. Disponível em: <ftp://geoftp.ibge.gov.br/mapeamento_sistematico/base_continua_ao_milionesimo/>. Acesso em: 05 mar. 2015.

INSTITUTO BRASILEIRO DE GEOGRAFIA E ESTATÍSTICA (IBGE). Cidades @. Disponível em <http://cidades.ibge.gov.br/v3/cidades/home-cidades> Acesso em: 22 Jan. 2017.

PREFEITURA DA ESTÂNCIA BALNEÁRIA DA ILHA COMPRIDA. Lei Orgânica do Município. Disponível em: <http://www.camarailhacomprida.sp.gov.br/lei-organica/>. Acesso em 20 Jan. 2017.

SÃO PAULO (ESTADO). Decreto Estadual $\mathbf{n}^{\circ} 28.881$ (1987). Lex: declara Área de Proteção Ambiental todo o território da Ilha Comprida. São Paulo, 1987.

SÃO PAULO (ESTADO). Decreto Estadual no 28.295 (1988). Lex: suspende o licenciamento e a aprovação de parcelamento de solo na Área de Proteção Ambiental da Ilha Comprida. São Paulo, 1988.

SÃO PAULO (ESTADO). Decreto Estadual n 30.817 (1989). Lex: regulamenta a Área de Proteção Ambiental da Ilha Comprida criada pelo Decreto $\mathrm{n}^{\circ}$ 26.881, de 11 de março de 1987, declara a mesma APA como de Interesse Especial e cria, em seu território, Reservas Ecológicas e Áreas de Relevante Interesse Ecológico. São Paulo, 1989.

SÃo PAUlo (ESTADO). APAS - Áreas de Proteção Ambiental: Território de Planejamento e Gestão Participativa. São Paulo: SMA, 2004.

SOUZA, T. A; OLIVEIRA, R. C. Avaliação da potencialidade de imagens tridimensionais em meio digital para o mapeamento geomorfológico. Revista Geonorte, Manaus, v. 2, n. 4, p.1348-1355, 2012.

SOUZA, T. A.; OLIVEIRA, R. C. O uso do sistema de informação geográfica aplicado à análise da erosão e da progradação costeira - a extremidade Nordeste da Ilha Comprida (São Paulo - Brasil) como estudo de caso. In: SIMPOSIO LATINOAMERICANO DE GEOGRAFÍA FÍSICA, SIMPOSIO IBEROAMERICANO DE GEOGRAFÍA FÍSICA, 8, 4., 2014, Santiago. Anales... Santiago: Facultad de Arquitectura y Urbanismo/Universidad de Chile, 2014. p. 382-391.

SOUZA, T. A.; OLIVEIRA, R. C. Modificações do uso da terra em paisagens costeiras: a Ilha Comprida (SP) como estudo de caso. Geographia Meridionalis, Pelotas, v. 2, n. 1, p.84-108, 2016.

SOUZA, T. A. Dinâmica geomorfológica e alterações antrópicas da Ilha Comprida. 2014. 195 f. Tese (Doutorado em Geografia) - Instituto de Geociências, Universidade Estadual de Campinas, Campinas.

TESSLER, M. G. et al. Evolução temporal e espacial da desembocadura lagunar de Cananeia (SP). Boletim do Instituto Oceanográfico, São Paulo, v. 38, n. 1, p.23-29, 1990. 